\title{
Endothelial Progenitor Cells Enhance the Migration and Osteoclastic Differentiation of Bone Marrow-Derived Macrophages in vitro and in a Mouse Femur Fracture Model through Talin-1
}

\author{
Yigong Cuia Shenglong Fu ${ }^{\mathrm{b}}$ Tianyong Hou ${ }^{\mathrm{a}}$ Xuehui Wu \\ aDepartment of Orthopaedics, Southwest Hospital, The Third Military Medical University, Chongqing, \\ bDepartment of Orthopaedics, Jinan Fifth People's Hospital, Shandong, China
}

\section{Key Words}

Endothelial progenitor cells $•$ Bone marrow-derived macrophages $•$ Osteoclastic differentiation - TGF- $\beta 1$ • Talin-1

\begin{abstract}
Background/Aims: Bone resorption mediated by osteoclasts plays an important role in bone healing. Endothelial progenitor cells (EPCs) promote bone repair by stimulating neovascularization and osteogenesis. However, the role of EPCs in osteoclast formation and function is not well defined. The aim of this study was to elucidate mechanisms of EPCs in osteoclast formation and function. Methods: In this study, we examined the effects of EPCs on the proliferation, migration and osteoclastic differentiation of primary mouse bone marrowderived macrophages (BMMs) in a co-culture system in vitro. We also evaluated the effects of EPC co-transplantation on the homing and osteoclastic differentiation of transplanted BMMs in a mouse bone fracture model in vivo. The technology of immunofluorescence, immunohistochemical, western blot, Rt-PCR, cell co-culture and Transwell were used in this study. Results: EPCs secreted TGF- $\beta 1$ in the EPC-BMM co-culture medium and increased Talin-1 expression in the co-cultured BMMs. Treatment with a TGF- $\beta 1$ neutralizing antibody or Talin-1 silencing in BMMs completely inhibited BMM osteoclastic differentiation in the co-culture system. These results indicated that the osteoclastogenic effects of EPCs were mediated by TGF- $\beta 1$-mediated Talin- 1 expression in BMMs. In the femur fracture model, BMMs co-transplanted with EPCs exhibited enhanced engraftment into the fracture site and osteoclastic differentiation compared with those transplanted alone. Mice treated with EPC-BMM co-transplantation exhibited increased neovascularization at the fracture site and accelerated fracture healing compared with those treated with BMMs alone. Conclusion: Taken

Y. Cui and S. Fu contributed equally to this work.

Tianyong Hou

and Xuehui Wu

Department of Orthopaedics, Southwest Hospital, The Third Military Medical University

Chongqing (China)

E-Mail tianyonghou@126.com; 2261775975@qq.com
\end{abstract}




\section{Cellular Physiology Cell Physiol Biochem 2018;49:555-564 \\ \begin{tabular}{ll|l} 
DOI: 10.1159/000492993 & Ond Biochemistry 2018 The Author(s). Published by S. Karger AG, Basel \\
wwww.karger.com/cpb
\end{tabular} \\ Published online: 29 August, 2018}

together, the results suggest that EPCs can promote bone repair by enhancing recruitment and differentiation of osteoclast precursors.

\section{Introduction}

Bone is one of the few tissues/organs that can undergo complete regeneration after injury [1]. Bone healing occurs through the coordinated activities of osteoclasts and osteoblasts to achieve site-directed removal of damaged bone by osteoclasts and subsequent bone formation by osteoblasts to replace the bone loss [2]. Osteoclasts are highly specialized, multinucleated cells that are derived from hematopoietic precursors of the monocyte-macrophage lineage residing in the bone marrow [3]. Osteoclast formation (osteoclastogenesis) depends on two essential cytokines: RANKL (receptor activator of nuclear factor (NF)- $\kappa B$ ligand) and M-CSF (macrophage colony-stimulating factor). RANKL, a tumor necrosis factor (TNF) family cytokine, directly controls osteoclast differentiation through activation of TNF receptor-associated factor (TRAF) 6, NF- $\mathrm{BB}$ (nuclear factor kappalight-chain-enhancer of activated B cells) and c-Fos [4]. M-CSF supports the survival and proliferation of the osteoclast precursor cells $[5,6]$ through activation of Mitf and Bcl-2 [7, 8]. The full differentiation and activation of osteoclasts require several additional signals that argument RANKL or M-CSF signaling [9]. For instance, TGF- $\beta$ has been reported to promote RANKL-induced osteoclastogenesis through SMAD2/SMAD3 [10], and $\beta 3$ integrins have been shown to regulate the differentiation and function of osteoclasts in concert with M-CSF $[11,12]$.

Endothelial progenitor cells (EPCs) give rise to functional endothelial cells to sustain vasculogenesis. They home to sites of vascular injury to engage in angiogenesis during the process of tissue remodeling and regeneration [13]. EPCs can promote neovascularization of tissue-engineered bones, and further improve osteogenesis and bone reconstruction [1416]. In addition, they can stimulate osteoblastic differentiation in vitro [17] and accelerate fracture healing in a segmental bone defect model in vivo [18]. Emerging evidence suggests that EPCs may also play a role in osteoclast formation and function. Specifically, EPCs have been reported to support the survival, migration, and differentiation of RAW 264.7 cells, a model of osteoclastic monocyte precursors, through multiple signaling pathways [19, 20]. However, whether EPCs can influence osteoclastogenesis by bone marrow-derived macrophages (BMMs) is not clear.

$\beta 3$ integrin signaling is a well-known mechanism regulating the formation and activity of osteoclasts $[12,21]$. Integrins use numerous cytosolic integrin-associated proteins (IAPs) to mediate their functions. Talin is the most important IAP that links $\beta$ integrins directly to actin, increasing the affinity of integrin for ligands and activating downstream events [22]. Studies have shown that Talin-1 plays a critical in the motility and bone resorption of osteoblasts [23, 24]. In this study, we investigated the role of EPCs in the survival, migration and osteoclastic differentiation of BMMs in vitro. We also evaluated the effects of EPC cotransplantation on the homing and osteoclastic differentiation of transplanted BMMs in a mouse bone fracture model in vivo. The underlying molecular mechanisms involving TGF- $\beta$ and Talin-1 were examined.

\section{Materials and Methods}

\section{Animals}

Six-week-old C57BL/10 mice were purchased from the Model Animal Research Center (MARC) of Nanjing University. All animal experiments were performed in accordance with the Institutional Guidelines for the Care and Use of Laboratory Animals of the Southwest Hospital, affiliated with the Third Military Medical University. All study protocols were reviewed and approved by the Animal Ethics Committee of the Southwest Hospital. 


\section{Cellular Physiology \begin{tabular}{ll|l} 
and Biochemistry & $\begin{array}{l}\text { DOI: 10.1159/000492993 } \\
\text { Published online: 29 August, } 2018\end{array}$ & $\begin{array}{l}\text { () 2018 The Author(s). Published by S. Karger AG, Basel } \\
\text { www.karger.com/cpb }\end{array}$ \\
\hline
\end{tabular}}

\section{Isolation and characterization of EPCS}

Mononuclear cells were isolated from mouse umbilical cord blood. Cells expressing the early EPC surface marker CD133 were selected using anti-CD133-coupled magnetic microbeads (Miltenyi Biotech, Bergisch Gladbach, Germany) and expanded in Dulbecco's Modified Eagle's medium (DMEM) supplemented with $10 \%$ fetal bovine serum (FBS). Immunophenotypic analysis was performed by staining $5 \times 10^{5}$ cells with monoclonal antibodies against CD31, CD34, CD133, vWF, and UFA-1, respectively (Sigma, St. Louis, MO, USA). Isotype-identical antibodies served as controls (PharMingen, San Diego, CA, USA). All cells were counterstained with the carbocyanine fluorescent dye Dil (Molecular Probes, Eugene, OR, USA). The angiogenic capacity of the early EPCs was determined by the Matrigel tube formation assay as we previously reported [19]. In brief, Matrigel (Sigma) was diluted in $500 \mu \mathrm{l} \mathrm{EGM-2} \mathrm{media}(1: 1 \mathrm{v} / \mathrm{v})$ in 96-well plates and incubated at $37^{\circ} \mathrm{C}$ for $1 \mathrm{~h}$ to allow polymerization. EPCs $\left(2 \times 10^{4}\right.$ cells/well $)$ were seeded onto the Matrigel and incubated at $37^{\circ} \mathrm{C}$ for $24 \mathrm{~h}$. Digital micrographs were taken for morphological analysis.

\section{BMM isolation and differentiation}

Mouse primary BMMs were prepared as previously described [24] with minor modifications. In brief, marrow was extracted from femora and tibiae of six-week-old C57BL/10 mice with $\alpha$-minimal essential medium ( $\alpha$-MEM) and placed in Petri dishes in a culture medium composed of $\alpha$-MEM supplemented with $10 \%$ inactivated fetal bovine serum (FBS), $100 \mathrm{IU} / \mathrm{ml}$ penicillin and $100 \mu \mathrm{g} / \mathrm{ml}$ streptomycin and CMG medium (conditioned medium containing $100 \mathrm{ng} / \mathrm{ml}$ mouse M-CSF) in a 1:10 ratio. Cells were incubated at $37^{\circ} \mathrm{C}$ with $5 \% \mathrm{CO}_{2}$ for 3 days, washed with phosphate-buffered saline (PBS) and harvested with trypsin/ EDTA (Invitrogen, Carlsbad, CA, USA).

To test the effects of EPCs on the proliferation and osteoclastic differentiation of BMMs, a co-culture system was established by inserting transwell chambers with $3 \mu \mathrm{m}$ pores (Millipore, Bedford, MA, USA) pre-seeded with EPCs $\left(1 \times 10^{3}\right.$ cells/chamber $)$ into 12 -well culture plates pre-seeded with BMMs $\left(1 \times 10^{3}\right.$ cells/well). DMEM ( $1 \mathrm{ml} /$ well) was subsequently added to cover both the EPCs and BMMs to allow crosstalk between the two cell types. Half of the medium was removed and replaced with fresh medium every two days. Cell proliferation was determined using the Cell Counting Kit-8 (CCK-8) assay. Osteoclastic differentiation was assessed by immunofluorescence staining for the osteoclast marker TRAP (tartrate acid resistant phosphatase) using anti-TRAP antibody (Sigma-Aldrich, St. Louis, MO, USA). BMMs cultured in medium containing GST-RANKL $(100 \mathrm{ng} / \mathrm{ml})$ and M-CSF $(30 \mathrm{ng} / \mathrm{ml})$ served as positive control for osteoclastic differentiation. TGF- $\beta 1$ levels in culture supernatants were determined by ELISA (Sigma-Aldrich, St. Louis, MO, USA). To test the effects of TGF- $\beta 1$ inhibition, cells were cultured in medium containing a neutralizing antibody toward TGF- $\beta 1$ (Sigma).

\section{Transwell migration assay}

The migration capacity of BMMs was measured using transwell inserts with a pore size of $8 \mu \mathrm{m}$ (Costar, Corning, NY). In brief, BMMs were loaded into the upper chamber and EPCs into the lower chamber. After incubation at $37^{\circ} \mathrm{C}$ with $5 \% \mathrm{CO}_{2}$ for 5 days, the BMMs were rinsed with PBS, fixed in $10 \%$ formalin for 10 $\mathrm{min}$, and stained with DAPI for $15 \mathrm{~min}$. The cells that had migrated to the lower surface of the membrane were counted in three randomly selected fields under an inverted light microscope (Leica, Germany) as previously described [25].

\section{RNA interference}

BMMs were collected and resuspended in Electroporation Isoosmolar Buffer (Eppendorf). The cells were transfected using electroporation with a Stealth RNAi ${ }^{\mathrm{TM}}$ small interfering RNA (siRNA) targeting Talin-1 (sense sequence: CAGCUCAUUGCUGGCUACAUAGAUA, Invitrogen) or a Stealth RNAi ${ }^{\mathrm{TM}}$ siRNA negative control (Med GC) on an ECM830 Electro-Square Porator (Harvard Apparatus). The electroporation was carried out using a single square wave pulse of $2,500 \mathrm{~V} / \mathrm{cm}$ field strength with $300 \mu$ s pulse length. After that, the cells were allowed to recover for $46 \mathrm{~h}$ in DMEM.

Western blot analysis

Cells were lysed and total proteins were quantified. Samples (30-50 $\mu$ g each) were separated by $10 \%$ SDS-PAGE (stacking gel $50 \mathrm{~V}$, separating gel $100 \mathrm{~V}$ ) and transferred to nitrocellulose membranes ( $100 \mathrm{~V}$ for 


\section{Cellular Physiology Cell Physiol Biochem 2018;49:555-564 \begin{tabular}{l|l|l} 
DOI: 10.1159/000492993 & $\begin{array}{l}\text { O 2018 The Author(s). Published by S. Karger AG, Basel } \\
\text { www.karger.com/cpb }\end{array}$
\end{tabular}}

Cui et al.: Epcs Promote Osteoclastogenesis through Talin-1

$75 \mathrm{~min}$ ). After blocking in defatted milk for $2 \mathrm{~h}$, the membranes were incubated with primary antibodies followed by horse radish peroxidase (HRP)-conjugated secondary antibodies. The protein bands were visualized using enhanced chemiluminescence. Densitometry analysis of protein levels was performed using Gel-pro Image Analysis Software (Media cybernetics, Rockville, MD, USA).

Preparation of green fluorescent protein (GFP)-labeled EPCs

EPCs were seeded in 24 -well plates $\left(5 \times 10^{4}\right.$ cells/well) and cultured until they reached $70 \%$ confluence. The cells were subsequently incubated with lentiviral vectors expressing GFP (Invitrogen) at a multiplicity of infection (MOI) of 20. The medium was replaced after $24 \mathrm{~h}$, and the fluorescence intensity was recorded after $96 \mathrm{~h}$. Uninfected EPCs served as negative control.

\section{Femur fracture model}

All surgical procedures were performed under normal aseptic conditions. Mice were anesthetized with intraperitoneal ketamine hydrochloride $(60 \mathrm{mg} / \mathrm{kg})$ and xylazine hydrochloride (10mg/kg). Femur fractures (unilateral) were produced by 3-point bending using the method described by Manigrasso [26]. Unfractured femurs served as negative control. Immediately after the fracture, mice received intravenous injection of BMMs $\left(2 \times 10^{5}\right.$ cells) suspended in Endothelial Basal Medium-2 (EBM-2, Lonza), either alone or in combination with GFP-labeled EPCs $\left(2 \times 10^{5}\right.$ cells $)$. To detect BMM homing to the fracture site, the cells were labeled with Dil (Molecular Probes) at $2.5 \mathrm{mg} / \mathrm{ml}$ for $5 \mathrm{~min}$ at $37^{\circ} \mathrm{C}$ followed by another $15 \mathrm{~min}$ at $4^{\circ} \mathrm{C}$ just before transplantation. To assess angiogenesis by EPCs, tissue samples were collected from the fracture site on day 7 or day 28 after cell transplantation, embedded in OCT compound (Sakura Finetek Japan, Tokyo, Japan), snap-frozen in liquid nitrogen and cut into 5- $\mu \mathrm{m}$-thick sections. The sections were stained with anti-CD31 antibody (Vector Laboratories, Burlingame, CA, USA), counterstained with DAPI, and examined under a fluorescence microscope. Dil-positive capillaries were counted in 10 randomly selected high-power fields. Talin-1 expression in BMMs was detected by immunofluorescence staining with anti-Talin-1 antibody (Vector Laboratories, Burlingame, CA, USA).

\section{Microcomputed tomography $(\mu \mathrm{CT})$}

The trabecular volumes at the distal femoral metaphysis and proximal tibia were determined using a Scanco CT40 scanner (Scanco Medical AG, Bassersdorf, Switzerland; threshold $=250$ ). Forty to 100 slices were analyzed, starting with the first slice in which condyles and primary spongiosa were no longer visible.

\section{Quantitative real-time PCR analysis}

RNA was isolated from BMMs or bone tissues using TRIZOL (Invitrogen). cDNA was synthesized from $1 \mu \mathrm{g}$ of total RNA in 21- $\mu$ l reaction volumes using oligo dT18 primers and SuperScript reverse transcriptase. PCR amplification was carried out with Taq DNA polymerase (TaKaRa) using $1 \mu \mathrm{l}$ of the first-strand cDNAs as templates. The amplification reactions were run with 30 thermocycles of $30 \mathrm{~s}$ at $94^{\circ} \mathrm{C}, 30 \mathrm{~s}$ at $55^{\circ} \mathrm{C}$ and $30 \mathrm{~s}$ at $72^{\circ} \mathrm{C}$. The primer sequences were: Car2, 5'-CATTACTGTCAGCAGCGAGCA-3' (sense) and 5'-GACGCCAGTTGTCCACCATC-3' (anti-sense); CTSK, 5'-CAGCAGAACGGAGGCATTGA-3' (sense) and 5'-CCTTTGCCGTGGCGTTATAC-3' (anti-sense); MMP9, 5'-GCCCTGGAACTCACACGACA-3' (sense) and 5'-TTGGAAACTCACACGCCAGAA-3' (anti-sense); TRAP, 5'-CAGTTGGCAGCAGCCAAGGAGGAC-3' (sense) and 5'-GTCCCTCAGGAGTCTAGGTATCAC-3' (anti-sense); GAPDH, 5'-CACAGTCAAGGCCGAGAATG-3' (sense) and 5'-TCGTGGTTCACACCCATCAC-3' (anti-sense).

Statistical analysis

All data are reported as the mean \pm SD. The Student's two-tailed unpaired $t$-test was applied to interpret differences between two groups. A p value less than 0.05 was regarded as statistically significant. 


\section{Cellular Physiology and Biochemistry Published online: 29 August, 2018 \begin{tabular}{l|l} 
DOI: 10.1159/000492993 2018 The Author(s). Published by S. Karger AG, Basel \\
www.karger.com/cpb
\end{tabular}}

Cui et al.: Epcs Promote Osteoclastogenesis through Talin-1

\section{Results}

\section{EPCs enhance the proliferation, migration and osteoclastic differentiation of co-cultured BMMS}

The $\mathrm{CD} 133^{+}$cells isolated from mouse umbilical cord blood exhibited a spindle-like morphology (Fig. 1A) and expressed a spectrum of EPC-specific surface markers including CD31, CD34, CD133, Flk-1, VEGFR2, vWF and UFA-1 (Fig. 1B-H). These cells also showed angiogenic potential as they formed tube-like structures on Matrigel (Fig. 1I). Compared with BMMs cultured alone, BMMs co-cultured with EPCs exhibited significantly increased cell proliferation and migration capacity (Fig. 2A-D). We subsequently assessed osteoclastic differentiation of BMMs by immunofluorescence staining for the osteoclast marker TRAP [27]. We found that co-culture with EPCs greatly enhanced the differentiation of BMMs into TRAP-positive multinucleated osteoclast-like cells, although the osteoclastogenic activity of EPCs was less potent compared with RANKL plus M-SCF (Fig. 3A, B).

\section{EPCs enhance osteoclastic differentiation of co-cultured BMMs through TGF- $\beta 1$-mediated}

Talin-1 signaling

ELISA revealed increased TGF- $\beta 1$ level in the EPC-BMM co-culture supernatant compared with BMM culture alone (Fig. 4A). Blocking TGF- $\beta 1$ signaling with a TGF- $\beta 1$ neutralizing antibody inhibited the differentiation of the co-cultured BMMs into TRAPpositive multinucleated osteoclast-like cells (Fig. 4B, C). Western blot analysis detected

Fig. 1. Culture and characterization of EPCs. $(\mathrm{A}-\mathrm{H})$ Representative microscopic images of EPCs (A) and immunofluorescence staining for the specific cell surface markers CD31 (B), CD34 (C), CD133 (D), Flk-1 (E), VEGFR2 (F), vWF (G) and UFA-1 $(\mathrm{H})$ after 7 days of growth in culture, magnification $400 \times$. (I) EPCs formed tube-like structures after $24 \mathrm{~h}$ of growth on Matrigel.

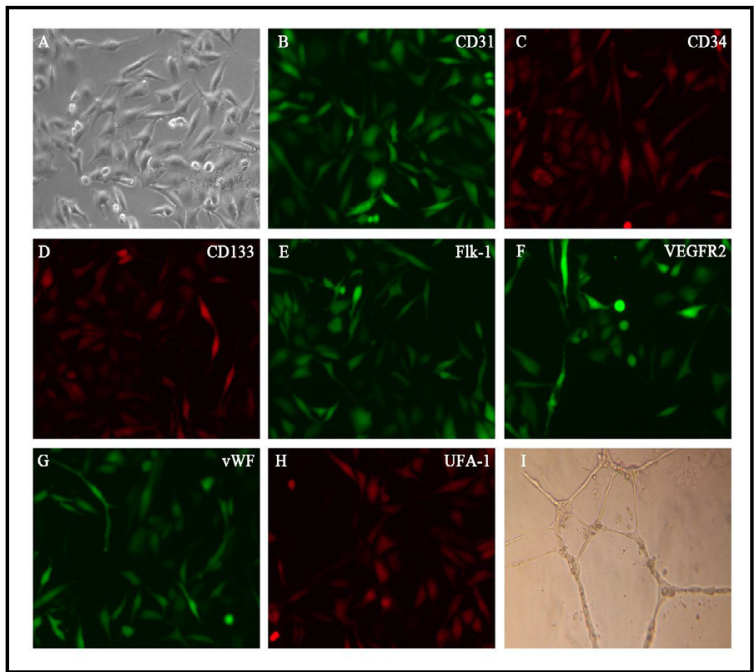

Fig. 2. EPCs enhance the proliferation and migration of co-cultured BMMs. (A-B) Representative microscopic images of BMMs after 7 days of growth (A, magnification $400 \times$ ) and cell proliferation determined by the CCK- 8 assay after 1,3 , 5 or 7 days of growth (B), with the cells either cultured alone (control) or cocultured with EPCs (co-culture). $\mathrm{n}=5$; ${ }^{*} \mathrm{p}<0.05,{ }^{* *} \mathrm{p}<0.01,{ }^{* * *} \mathrm{p}<0.001$ vs. control.

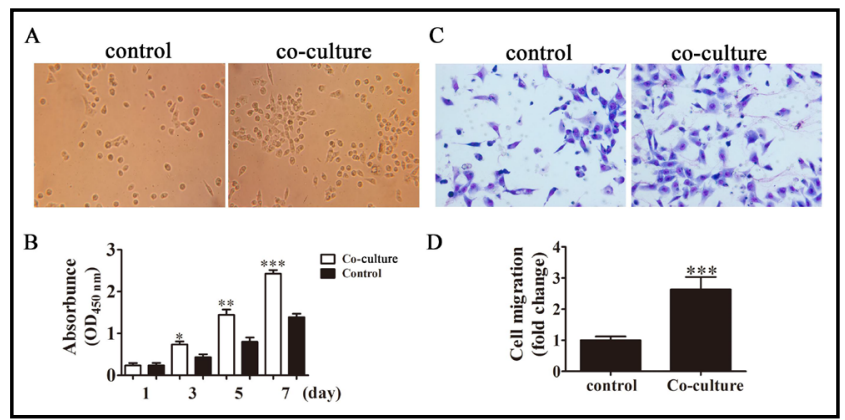
(C-D) Representative images of BMMs (stained with crystal violet) on the lower surface of the transwell membrane (C) and quantitative analysis of cell migration by cell counting (D) after 5 days in culture, with the cells either cultured alone (control) or co-cultured with EPCs (co-culture). $\mathrm{n}=3,{ }^{* * *} \mathrm{p}<0.001$ vs. control.

\section{KARGER}


Fig. 3. EPCs promote osteoclastic differentiation of co-cultured BMMs. (A-B) Representative immunofluorescence images of TRAP (A, magnification 200x) and the numbers of TRAP-positive multinucleated ( $\geq 3$ nuclei) cells (B) of BMMs after 7 days of

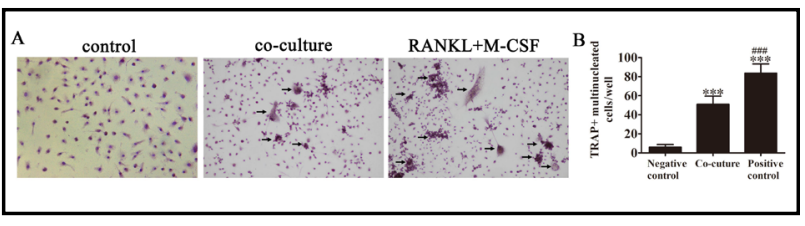
culture, with the cells either cultured alone (control), co-cultured with EPCs (co-culture), or cultured with GST-RANKL (100 ng/ml) and M-CSF (30 ng/ml) (RANKL+M-CSF). $\mathrm{n}=3$, ${ }^{* * *} \mathrm{p}<0.001$ vs. control, ${ }^{\# \# \# p<0.001}$ vs. co-culture. The arrows indicate TRAP-positive multinucleated osteoclast-like cells.

Fig. 4. EPC-derived TGF- $\beta 1$ promotes BMM osteoclastic differentiation through Talin-1. (A) TGF- $\beta 1$ levels in BMM culture supernatants by ELISA. BMMs were either cultured alone (control) or cocultured with EPCs (co-culture) for 7 days. (B-D) The numbers of TRAP-positive multinucleated ( $\geq 3$ nuclei) cells (B), representative immunohistochemical images of TRAP (C) and Talin-1 expression (Western blot analysis) (D) of BMMs after 7 days of culture. The cells were either cultured alone (control), cocultured with EPCs (co-culture) or co-cultured with EPCs in the presence of a TGF- $\beta 1$ neutralizing antibody (TGF- $\beta 1$ inhibitor). (E,F) The numbers of TRAP-positive multinucleated ( $\geq 3$ nuclei) cells (E) and representative immunohistochemical images of TRAP (F) of BMMs after 7 days of culture. The cells were either cultured alone (control), co-cultured with EPCs (co-culture) or transfected with a Talin1-targeting siRNA prior to co-culture with EPCs

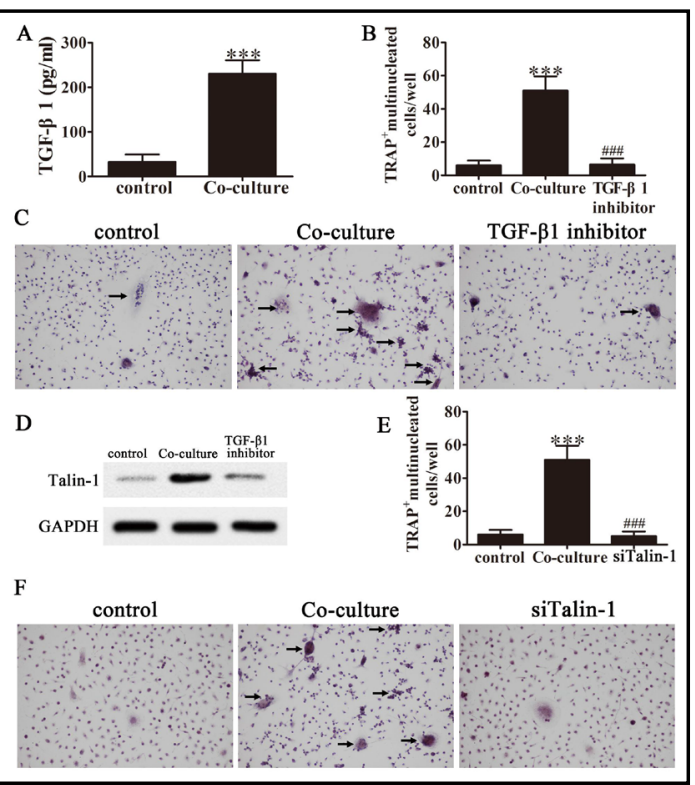
(siTalin-1). $\mathrm{n}=3,{ }^{* * *} \mathrm{p}<0.001$ vs. control, ${ }^{\# \# \#} \mathrm{p}<0.001$ vs. co-culture.

increased Talin-1 expression in the co-cultured BMMs compared with BMMs cultured alone, and incubation with the TGF- $\beta 1$ neutralizing antibody blocked Talin-1 expression in the cocultured BMMs (Fig. 4D). Similar to treatment with the TGF- $\beta 1$ neutralizing antibody, Talin-1 knockdown by siRNA transfection in BMMs prevented the osteoclastic differentiation of the co-cultured BMMs (Fig. 4E, F). The result show that compared with control or negative control (NC). The expression of Talin-1 was signifigantly decreased in both protein and mRNA level (Fig. 5). In addition, compared with BMMs cultured alone, BMMs co-cultured with EPCs exhibited increased mRNA and protein expression of the osteoclast genes MMP9, CTSK, TRAP, and Car2, and treatment with the TGF- $\beta 1$ neutralizing antibody or Talin-1 knockdown prevented the expression of these osteoclast genes (Fig. 6A-E). Collectively, these data indicated that EPCs promote osteoclastic differentiation of the co-cultured BMMs through TGF- $\beta 1$ secretion and consequent upregulation of BMM Talin-1 expression.

EPC co-transplantation promotes the homing and osteoclastic differentiation of BMMs, and further accelerates bone healing

Four weeks after cell transplantation, femur fractures treated with Dil-labeled BMMs along with GFP-labeled EPCs exhibited better bone healing than those treated with Dillabeled BMMs alone (Fig. 7A). Transplantation of BMMs alone led to partial fracture repair, while BMM-EPC co-transplantation resulted in formation of continuous new bone that covered the entire fracture area. Seven days after transplantation, mice treated with BMMEPC co-transplantation showed a greater number of Dil-labeled BMMs with higher Talin-1 expression around the fracture site than those treated with BMM transplantation alone (Fig. 


\section{Cellular Physiology

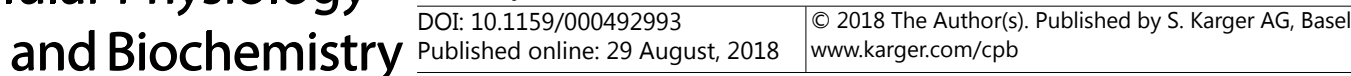

Cui et al.: Epcs Promote Osteoclastogenesis through Talin-1

Fig. 5. The expression of Talin-1 were detected after transfected with siRNA aganist Talin-1 vector. (A and B) Western blot (A) and qRt-PCR (B) detection the expression of Talin-1 after transfected with siRNA against Talin-1 for $48 \mathrm{~h}$.

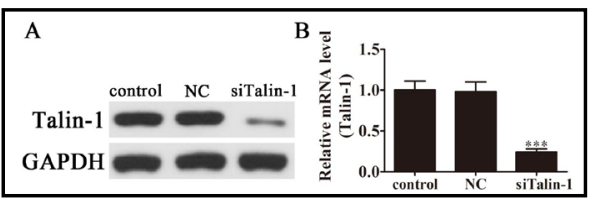

Fig. 6. EPCs promote osteoclast gene expression in co-cultured BMMs through TGF- $\beta 1$-mediated Talin-1 signaling. (A-E) The mRNA levels of the osteoclast genes MMP9 (A), CTSK (B), TRAP (C) and Car2 (D) by quantitative RT-PCR and the protein levels of these genes by western blot analysis (E) in BMMs after 7 days of culture. The cells were either cultured alone (control), co-cultured with EPCs (coculture), co-cultured with EPCs in the presence of a TGF- $\beta 1$ neutralizing antibody (TGF- $\beta 1$ inhibitor) or transfected with a Talin-1-targeting siRNA prior to co-culture with EPCs (siTalin-1). GAPDH was used as controls. $\mathrm{n}=3 ;{ }^{* *} \mathrm{p}<0.01,{ }^{* * *} \mathrm{p}<0.001$ vs. control.

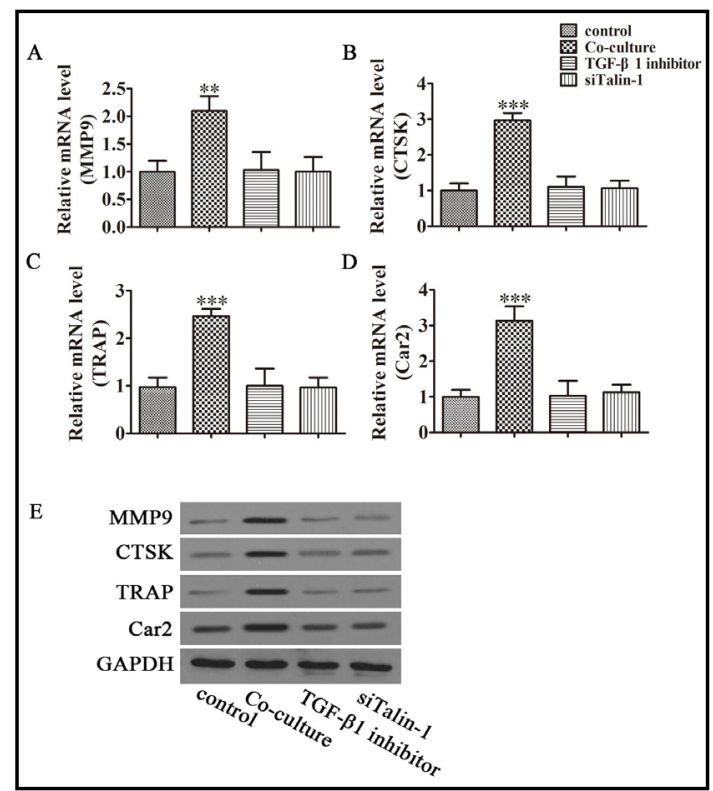

Fig. 7. EPC co-transplantation promotes the homing and osteoclastic differentiation of transplanted BMMs, and further accelerates bone healing. Mice received intravenous transplantation of Dil-labeled BMMs, either alone (control) or in combination with GFP-labeled EPCs (co-culture), immediately after femur fracture. (A) Representative $\mu \mathrm{CT}$ images of the fractured femur at week 4. (B) Immunofluorescence staining for Talin-1 expression in Dil-labeled BMMs around the fracture site at day 7. (C) Representative fluorescence images of GFP and immunofluorescence images of CD31 of tissues at the fracture site at week 4. Tissues were counterstained with DAPI. (D) Density of Dil-positive capillaries at the fracture site at week 4. (E-H) The relative mRNA levels of TGF- $\beta 1$ (E), MMP9 (F), TRAP (G) and CTSK (H) in tissues at the fracture site at day 7 by qRT-PCR. $n=3{ }^{* *} \mathrm{p}<0.01$, $* * * \mathrm{p}<0.001$ vs. control.

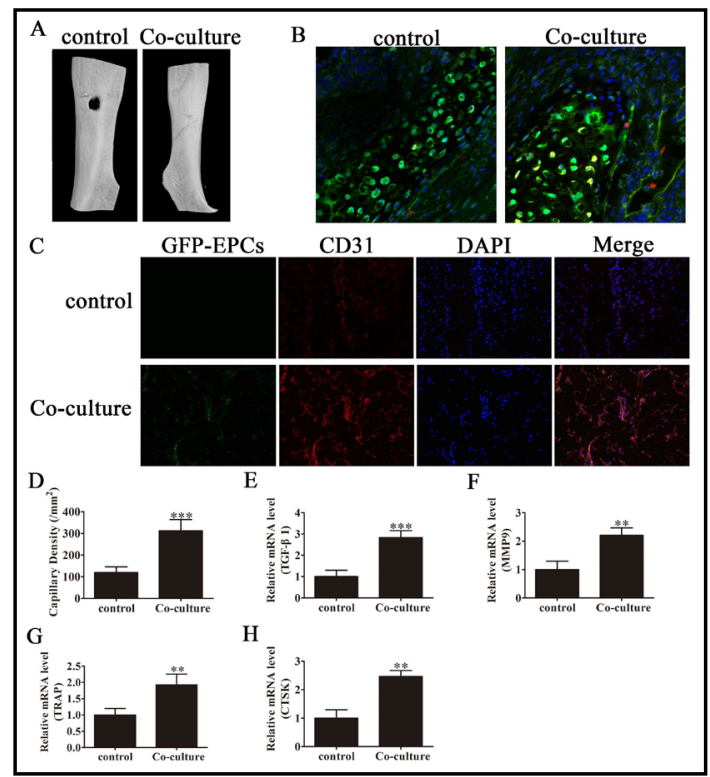

7B), indicating that EPC co-transplantation promoted the homing of the transplanted BMMs to the injury site and stimulated Talin-1 expression in engrafted cells. The BMM-EPC cotransplantation group also exhibited increased CD31 immunofluorescence at the fracture site 4 weeks after transplantation, especially in areas where GFP-labeled EPCs were detected (Fig. 7C). Interestingly, significant amounts of engrafted BMMs were detected around newlyformed capillaries at the fracture site in both treatment groups, with a higher density of such capillaries observed in the BMM-EPC co-transplantation group (Fig. 7D). These data suggested that the engrafted BMMs directly enhanced neovascularization at the fracture site 
by paracrine mechanisms. In keeping with our in vitro data, mice treated with BMM-EPC co-transplantation showed higher mRNA levels of TGF- $\beta 1$ and the osteoclast genes MMP9, TRAP and CTSK at the fracture site than those treated with BMM transplantation alone (Fig. 7E-H).

\section{Discussion}

In animal models, EPCs have been shown to promote bone repair through a variety of mechanisms, by differentiating into endothelial cells and osteoblasts to enhance neovascularization and osteogenesis, as well as stimulating supporting cells by paracrine mechanisms through the secretion of growth factors and cytokines [28, 29]. They have also been reported to enhance osteogenic differentiation capacities of osteoblast precursors in vitro and in vivo $[17,30]$. With regard to the role of EPCs in osteoclast formation and function, previous reports have shown that EPCs support the survival, migration, and differentiation of RAW 264.7 cells, a model of osteoclastic monocyte precursors [19, 20]. In this study, we found that EPCs derived from mouse umbilical cord blood promoted the proliferation, migration and osteoclastic differentiation of primary mouse BMMs in a EPC-BMM coculture system. In keeping with these in vitro results, co-transplantation of EPCs enhanced the homing and osteoclastic differentiation of transplanted BMMs in a mouse femur fracture model, and further accelerated fracture healing.

TGF- $\beta$ has been documented to regulate osteoclastogenesis by activating Smad $2 / 3$ [10]. In Pang's report [19], EPCs secreted VEGF-A, SDF-1 and TGF- $\beta 1$ in the EPC-RAW 264.7 coculture system and increased levels of phospho-Smad2/3, phospho-Akt, phospho-ERK1, and phospho-p38 MAPK in the co-cultured RAW 264.7 cells. These data supported the TGF- $\beta 1-$ Smad2/3 signaling pathway as a potential mediator of the osteoclastogenic effects of EPCs on the co-cultured RAW 264.7. In this study, EPCs secreted TGF- $\beta 1$ in the EPC-BMM co-culture system, and the osteoclastogenic effects of EPCs on the co-cultured BMMs were completely blocked by treatment with a TGF- $\beta 1$ neutralizing antibody. Taken together, these findings strongly suggest that EPCs stimulate differentiation of surrounding osteoclast precursors by paracrine mechanisms through the secretion of TGF- $\beta 1$.

Talin-1 is a fundamental protein component of the osteoclast cytoskeleton, and as such plays a critical role in the adhesion, motility and bone resorption of osteoblasts [23, 24]. We found that EPCs increased Talin-1 expression in the co-cultured BMMs through a TGF$\beta 1$-depedent mechanism, and similar to TGF- $\beta 1$ neutralizing antibody treatment, Talin-1 silencing in BMMs completed prevented osteoclastic differentiation of BMMs co-cultured with EPCs. Thus, Talin- 1 acts downstream of TGF- $\beta 1$ in mediating the osteoclastogenic effects of EPCs. The molecular mechanisms by which TGF- $\beta 1$ increases Talin- 1 expression in BMMs are currently unclear, and thus, require further investigation.

In the femur fracture model, BMMs co-transplanted with EPCs exhibited enhanced engraftment into the fracture site and osteoclastic differentiation compared with those transplanted alone. Co-transplantation of BMMs and EPCs also led to increased neovascularization at the injury site compared with BMM transplantation alone. We believe that the accelerated fracture healing achieved by the co-transplantation therapy was attributed to increased neovascularization as well as enhanced osteoclastic activity at the injury site.

Phase I/IIa clinical trials applying granulocyte colony stimulating factor-mobilized EPCs to nonunion bone fractures have generated accelerated fracture healing with minimal adverse effects [31]. Our findings shed new light on the mechanisms by which EPCs promote bone repair and support EPC-based therapy in orthopaedics. 


\section{Cellular Physiology Cell Physiol Biochem 2018;49:555-564 \\ \begin{tabular}{l|l|l} 
and Biochemistry & $\begin{array}{l}\text { DOI: 10.1159/000492993 } \\
\text { Published online: 29 August, } 2018\end{array}$ & $\begin{array}{l}\text { C) } 2018 \text { The Author(s). Published by S. Karger AG, Basel } \\
\text { www.karger.com/cpb }\end{array}$ \\
\hline
\end{tabular}}

Cui et al.: Epcs Promote Osteoclastogenesis through Talin-1

\section{Acknowledgements}

This study was supported by the National Natural Science Foundation of China (Grant no. 81472075).

$\mathrm{TH}$ and $\mathrm{HW}$ originated the idea and performed preliminary experiments. TH and $\mathrm{YC}$ continued to perform the experiments. YC and SF coordinated the laboratory support. YC and TH were responsible for writing the paper. YC supported the editing of the manuscript and added important comments to the paper. All authors read and approved the final manuscript.

\section{Disclosure Statement}

The authors declare to have no competing interests.

\section{References}

1 Marsell R, Einhorn TA: The biology of fracture healing. Injury 2011;42:551-555.

2 Sims NA, Martin TJ: Coupling the activities of bone formation and resorption: A multitude of signals within the basic multicellular unit. Bonekey Rep 2014;3:481.

3 Boyle WJ, Simonet WS, Lacey DL: Osteoclast differentiation and activation. Nature 2003;423:337-342.

4 Asagiri M, Takayanagi H: The molecular understanding of osteoclast differentiation. Bone 2007;40:251264.

5 Yoshida H, Hayashi S, Kunisada T, Ogawa M, Nishikawa S, Okamura H, Sudo T, Shultz LD: The murine mutation osteopetrosis is in the coding region of the macrophage colony stimulating factor gene. Nature 1990;345:442-444.

-6 Lagasse E, Weissman IL: Enforced expression of bcl-2 in monocytes rescues macrophages and partially reverses osteopetrosis in op/op mice. Cell 1997;89:1021-1031.

-7 Weilbaecher KN, Motyckova G, Huber WE, Takemoto CM, Hemesath TJ, Xu Y, Hershey CL, Dowland NR, Wells AG, Fisher DE: Linkage of m-csf signaling to mitf, tfe3, and the osteoclast defect in $\mathrm{mitf}(\mathrm{mi} / \mathrm{mi}) \mathrm{mice}$. Mol Cell 2001;8:749-758.

-8 McGill GG, Horstmann M, Widlund HR, Du J, Motyckova G, Nishimura EK, Lin YL, Ramaswamy S, Avery W, Ding HF, Jordan SA, Jackson IJ, Korsmeyer SJ, Golub TR, Fisher DE: Bcl2 regulation by the melanocyte master regulator mitf modulates lineage survival and melanoma cell viability. Cell 2002;109:707-718.

9 Kim JH, Kim N: Signaling pathways in osteoclast differentiation. Chonnam Med J 2016;52:12-17.

-10 Yasui T, Kadono Y, Nakamura M, Oshima Y, Matsumoto T, Masuda H, Hirose J, Omata Y, Yasuda H, Imamura T, Nakamura K, Tanaka S: Regulation of rankl-induced osteoclastogenesis by tgf-beta through molecular interaction between smad3 and traf6. J Bone Miner Res 2011;26:1447-1456.

11 Faccio R, Takeshita S, Zallone A, Ross FP, Teitelbaum SL: C-fms and the alphavbeta3 integrin collaborate during osteoclast differentiation. J Clin Invest 2003;111:749-758.

12 Ross FP, Teitelbaum SL: Alphavbeta3 and macrophage colony-stimulating factor: Partners in osteoclast biology. Immunol Rev 2005;208:88-105.

13 George AL, Bangalore-Prakash P, Rajoria S, Suriano R, Shanmugam A, Mittelman A, Tiwari RK: Endothelial progenitor cell biology in disease and tissue regeneration. J Hematol Oncol 2011;4:24.

14 Yu H, Vandevord PJ, Gong W, Wu B, Song Z, Matthew HW, Wooley PH, Yang SY: Promotion of osteogenesis in tissue-engineered bone by pre-seeding endothelial progenitor cells-derived endothelial cells. J Orthop Res 2008;26:1147-1152.

15 Pang H, Wu XH, Fu SL, Luo F, Zhang ZH, Hou TY, Li ZQ, Chang ZQ, Yu B, Xu JZ: Prevascularisation with endothelial progenitor cells improved restoration of the architectural and functional properties of newly formed bone for bone reconstruction. Int Orthop 2013;37:753-759.

16 Goerke SM, Obermeyer J, Plaha J, Stark GB, Finkenzeller G: Endothelial progenitor cells from peripheral blood support bone regeneration by provoking an angiogenic response. Microvasc Res 2015;98:40-47. 


\section{Cellular Physiology Cell Physiol Biochem 2018;49:555-564 \begin{tabular}{l|l} 
DOI: 10.1159/000492993 & $\begin{array}{l}\text { O 2018 The Author(s). Published by S. Karger AG, Basel } \\
\text { www.karger.com/cpb }\end{array}$
\end{tabular}}

Cui et al.: Epcs Promote Osteoclastogenesis through Talin-1

17 Lee JH, Hah YS, Cho HY, Kim JH, Oh SH, Park BW, Kang YH, Choi MJ, Shin JK, Rho GJ, Jeon RH, Lee HC, Kim GC, Kim UK, Kim JR, Lee CI, Byun JH: Human umbilical cord blood-derived cd34-positive endothelial progenitor cells stimulate osteoblastic differentiation of cultured human periosteal-derived osteoblasts. Tissue Eng Part A 2014;20:940-953.

$>18$ Atesok K, Li R, Stewart DJ, Schemitsch EH: Endothelial progenitor cells promote fracture healing in a segmental bone defect model. J Orthop Res 2010;28:1007-1014.

19 Pang H, Wu XH, Fu SL, Luo F, Zhang ZH, Hou TY, Li ZQ, Chang ZQ, Yu B, Xu JZ: Co-culture with endothelial progenitor cells promotes survival, migration, and differentiation of osteoclast precursors. Biochem Biophys Res Commun 2013;430:729-734.

-20 Fu SL, Pang H, Xu JZ, Wu XH: C/ebpbeta mediates osteoclast recruitment by regulating endothelial progenitor cell expression of sdf-1alpha. PLoS One 2014;9:e91217.

-21 McHugh KP, Hodivala-Dilke K, Zheng MH, Namba N, Lam J, Novack D, Feng X, Ross FP, Hynes RO, Teitelbaum SL: Mice lacking beta3 integrins are osteosclerotic because of dysfunctional osteoclasts. J Clin Invest 2000;105:433-440.

22 Klapholz B, Brown NH: Talin - the master of integrin adhesions. J Cell Sci 2017;130:2435-2446.

23 Lakkakorpi PT, Vaananen HK: Kinetics of the osteoclast cytoskeleton during the resorption cycle in vitro. J Bone Miner Res 1991;6:817-826.

24 Zou W, Izawa T, Zhu T, Chappel J, Otero K, Monkley SJ, Critchley DR, Petrich BG, Morozov A, Ginsberg MH, Teitelbaum SL: Talin1 and rap1 are critical for osteoclast function. Mol Cell Biol 2013;33:830-844.

25 Gordillo G, Fang H, Khanna S, Harper J, Phillips G, Sen CK: Oral administration of blueberry inhibits angiogenic tumor growth and enhances survival of mice with endothelial cell neoplasm. Antioxid Redox Signal 2009;11:47-58.

-26 Manigrasso MB, O'Connor JP: Characterization of a closed femur fracture model in mice. J Orthop Trauma 2004;18:687-695.

-27 Minkin C: Bone acid phosphatase: Tartrate-resistant acid phosphatase as a marker of osteoclast function. Calcif Tissue Int 1982;34:285-290.

28 Atesok K, Matsumoto T, Karlsson J, Asahara T, Atala A, Doral MN, Verdonk R, Li R, Schemitsch E: An emerging cell-based strategy in orthopaedics: Endothelial progenitor cells. Knee Surg Sports Traumatol Arthrosc 2012;20:1366-1377.

29 Kawakami Y, Matsumoto T, Mifune Y, Fukui T, Patel KG, Walker GN, Kurosaka M, Kuroda R: Therapeutic potential of endothelial progenitor cells in the field of orthopaedics. Curr Stem Cell Res Ther 2017;12:3-13.

30 Liang Y, Wen L, Shang F, Wu J, Sui K, Ding Y: Endothelial progenitors enhanced the osteogenic capacities of mesenchymal stem cells in vitro and in a rat alveolar bone defect model. Arch Oral Biol 2016;68:123-130.

-31 Kuroda R, Matsumoto T, Niikura T, Kawakami Y, Fukui T, Lee SY, Mifune Y, Kawamata S, Fukushima M, Asahara T, Kawamoto A, Kurosaka M: Local transplantation of granulocyte colony stimulating factormobilized cd34+ cells for patients with femoral and tibial nonunion: Pilot clinical trial. Stem Cells Transl Med 2014;3:128-134. 